Article

\title{
Analysis of Flavonoids Bioactivity for Cholestatic Liver Disease: Systematic Literature Search and Experimental Approaches
}

\author{
Juan Carlos Sánchez-Salgado ${ }^{1,2, *}$, Samuel Estrada-Soto ${ }^{2, * \mathbb{C}}$, Sara García-Jiménez ${ }^{2}$, \\ Sergio Montes ${ }^{3}$ (D) Jaime Gómez-Zamudio ${ }^{4}$ (D) and Rafael Villalobos-Molina ${ }^{5,6}$ \\ 1 Instituto de Medicina Molecular y Ciencias Avanzadas, Mexico City 01900, Mexico \\ 2 Facultad de Farmacia, Universidad Autónoma del Estado de Morelos, Cuernavaca, MOR 62209, Mexico; \\ saragarcia@uaem.mx \\ 3 Instituto Nacional de Neurología y Neurocirugía, Mexico City 14269, Mexico; montesergio@yahoo.com \\ 4 Unidad de Investigación Médica en Bioquímica, Hospital de Especialidades, \\ Centro Médico Nacional Siglo XXI, IMSS, México City 06720, Mexico; \\ jaime_gomez_zamudio@hotmail.com \\ 5 Unidad de Biomedicina, Facultad de Estudios Superiores-Iztacala, Universidad Nacional Autónoma de \\ México, Tlalnepantla 54090, Mexico; villalobos@campus.iztacala.unam.mx \\ 6 Departamento de Bioquímica, Facultad de Medicina, Universidad Nacional Autónoma de México, \\ Ciudad de México 04510, México \\ * Correspondence: juanc.sanchez@immca.com.mx (J.C.S.-S.); enoch@uaem.mx (S.E.-S.); \\ Tel.: +52-777-329-7089 (S.E.-S)
}

Received: 2 December 2018; Accepted: 7 March 2019; Published: 14 March 2019

check for updates

\begin{abstract}
Flavonoids are naturally occurring compounds that show health benefits on the liver. However, there is little investigation about identification and evaluation of new flavonoid-containing drugs for cholestatic liver disease, one of the most common liver illnesses. We aimed to a systematic search regarding efficacy of flavonoids for treatment of cholestatic liver disease, and then evaluate naringenin (NG) as representative flavonoid in an obstructive cholestasis model. We searched for information of experimental and clinical studies in four major databases without time and language limits. Intervention was defined as any flavonoid derivate compared with other flavonoid, placebo, or without comparator. In addition, we evaluated NG on a bile duct-ligated model in order to contribute evidence of its actions. Eleven experimental reports that support the efficacy of flavonoids in cholestatic liver disease were identified. However, there was no homogeneity in efficacy endpoints evaluated and methodology. On the other hand, NG showed beneficial effects by improving specific metabolic (cholesterol and lipoproteins) and liver damage (bilirubin and alkaline phosphatase) biomarkers. The review lacks homogeneous evidence about efficacy of flavonoids in experimental settings, and is susceptible to risk for bias. NG only showed improvements in specific disease biomarkers. More investigation is still needed to determine its potential for drug development.
\end{abstract}

Keywords: flavonoids; systematic review; cholestasis

\section{Introduction}

Liver disease is a prominent health problem with an important epidemiological and economic burden worldwide, accounting for $25 \%$ of prevalence [1,2]. However, this estimation is inconsistent since there is no reliable and applicable diagnostic test yet [2].

Cholestasis is an impaired bile flow from liver to duodenum that triggers unspecific cellular damage, which initiates inflammatory and fibro-genic processes in the liver, as well as cirrhosis and 
hepatocellular cancer in advanced stages [3]. This alteration might be provoked by an impaired export of bile acids to bile canaliculi (intrahepatic cholestasis), or by physical obstruction of bile flow due to gall stones, parasites, or biliary tumor growth (extrahepatic cholestasis) [4].

The most accepted and well established experimental model that reproduces pathobiochemical alterations is the bile duct-ligated (BDL) rodent model [3,5]. The surgical bile duct ligation induces an obstructive cholestatic damage, which results in typical phenotype as in human cholestasis $[3,5,6]$. In this context, there are exhaustive efforts to found new therapeutic agents able to decrease pathological severity and progression of cholestatic liver diseases. Despite this, there are limited approved drug interventions for the treatment of this disease, i.e., ursodeoxycholic acid (UDCA) is the only approved oral drug for cholestatic liver diseases, such as primary biliary cirrhosis and obstructive cholestasis $[7,8]$. Additionally, silymarin, a mixture of flavolignans from Silybum marianum (milk thistle), has been proposed as an alternative for primary biliary cirrhosis due to its antioxidant and hepatoprotective properties [9-11].

Systematic reviews and meta-analysis have become increasingly important in decision making for drug discovery. In fact, this technique is a powerful evidence-based strategy to ensure there is justification for further research on bioactive molecules or re-planning research objectives [12]. A little investigation has been carried out on flavonoid efficacy in disease. Only a systematic review summarizes biological activities of prenylated flavonoids and suggests the structural implications for their bioactivities [13]. However, there is no information about efficacy of these compounds on cholestatic liver disease despite previous evidence for silymarin.

Previously we reported the beneficial effects of flavonoid-rich extract of Cochlospermum vitifolium bark for improvement of liver enzymes activity in BDL rat [14]. Then, HPLC analysis showed that one of its main bioactive compounds was naringenin (NG), a widely spread flavonoid in nature [15]. Recently, a chemical analysis revealed the presence of other flavonoids in the bark extract of this species [16].

This work summarizes and compares the efficacy endpoints reported for flavonoids in cholestatic liver disease, taking into account clinical and experimental settings, by systematic literature search in four major databases. Moreover, we evaluated the efficacy of NG in a BDL Wistar rat model in order to compare retrieved information from literature. To the best of our knowledge, this is the first systematic search of flavonoids as candidates for cholestasis therapy, as well as to show the biological effects of NG on the BDL rat.

\section{Materials and Methods}

\subsection{Systematic Review}

\subsubsection{Sources}

We conducted a systematic search for peer-reviewed articles in four major databases: Pubmed (Medline), Cochrane Library, Trip Database, and Lilacs. PRISMA statement was followed in order to establish the evidence-based minimum set of items for reporting on systematic reviews.

\subsubsection{Eligibility Criteria}

A PICO strategy was developed as described in Table S1. Briefly, the databases were searched using combinations of the following terms: flavonoid, cholestasis, and bile duct ligated. A species filter for human or animal was applied to identify clinical trials or experimental assays, respectively. Simple literature reviews, case reports, editorial letters, comments, as well as duplicated or no abstract articles were excluded. The searching did not consider time and language limits. 


\subsubsection{Studies Selection}

The inclusion criteria for the selection of manuscripts were: all articles containing keywords in title, abstract or full-text, as well as those reporting clinical trials or experimental studies of isolated flavonoids for the treatment of cholestatic liver diseases (primary biliary cirrhosis, primary sclerosing cholangitis, biliary atresia, or Alagille syndrome). Only with BDL were selected in order to compare our experimental data. The selection was conducted by two independent reviewers, who analyzed the articles for discrepancies.

\subsubsection{Meta-Analysis}

A meta-analysis of the retrieved data could not be carried out due to methodological heterogeneity such as dosing, mode of administration, animal species, and time of exposure.

\subsubsection{Risk of Bias Assessment}

In order to assess the risk of biases of the animal studies reported in this systematic review, we applied a modified version of Cochrane's RoB tool denominated Systematic Review Centre for Laboratory animal Experimentation (SYRCLE). This tool considers six types of biases: Selection, performance, detection, attrition, reporting, and other biases, comprised of 10 items [17].

\subsection{Experimental Studies}

\subsubsection{Reagents and Materials}

Naringenin $\sim 95 \%$ were purchased from Sigma-Aldrich Co. (St. Louis, MO, USA). Other reagents and surgical supplies were purchased from local sources.

\subsubsection{Sample Preparation}

Briefly, test samples were dissolved using a $10 \%$ aqueous solution of dimethylsulfoxide (DMSO). Dose of NG used was $50 \mathrm{mg} / \mathrm{kg} /$ day; the control group received $2 \mathrm{~mL}$ of vehicle.

\subsubsection{Animal Model}

Male Wistar rats (250-300 g, b.w.) were used under laboratory conditions with standard rodent diet and water ad libitum. All of the protocols were conducted as established by Federal Regulations for Animal Experimentation and Care (NOM-062-ZOO-1999, SAGARPA) and approved by Scientific and Bioethics Committee of Facultad de Farmacia (UAEM).

All animals were anesthetized by intraperitoneal injection of sodium pentobarbital $(35 \mathrm{mg} / \mathrm{kg})$, shaved and sanitized using a surgical disinfecting solution. A $1 \mathrm{~cm}$ incision below xiphoid process was made to extract gastrohepatic epiplon and locate duodenum segment. Once bile duct was cleaned for connective tissue, a triple ligation was made on bile duct using non-absorbable monofilament nylon suture (Farmacéutica Internacional S.A. de C.V., Mexico City, Mexico), and cut in two segments. Unconscious animals were gently sutured and allocated in warmed room until recovery. Sham animals (surgery control group) were subjected to the same protocol, but without ligation.

After $24 \mathrm{~h}$ post-surgery, animals were randomly allocated in three experimental groups $(n=10$ animals per group) and began to receive the treatment. The experimental groups were: Sham + vehicle, $\mathrm{BDL}+$ vehicle, and BDL + NG. Aseptic cleaning was made along experiments using povidone-iodine $10 \%$ solution as palliative care. After 10 days of treatment all animals were sacrificed by dislocation and blood samples extracted by cardiac puncture. ARRIVE guidelines were followed for reporting this assay. 


\subsubsection{Biomarkers Quantification}

Fresh collected blood samples were centrifuged at $3000 \mathrm{~g}$ for $10 \mathrm{~min}$. Serum was separated from cell fraction and stored at $-20{ }^{\circ} \mathrm{C}$ until analysis. Non-specific cholestasis biomarkers alanine transaminase (ALT), aspartate transaminase (AST), alkaline phosphatase (AP), and $\gamma$-glutamyltranspeptidase (GGT) activities) were determined as described by Rivera-Macías et al. [18].

Additionally, metabolic biomarkers were determined such as glucose, total cholesterol, triglycerides, very low-density lipoprotein (VLDL), high-density lipoprotein (HDL), and low-density lipoprotein (LDL). Quantitative enzymatic spectrophotometry was carried out using commercial kits (Wiener Labs, Mexico City, Mexico).

\subsubsection{Data Analysis and Statistics}

Data shown are expressed as mean \pm standard error of the mean (SEM) obtained from three independent experiments. Plots were constructed with Microcal ${ }^{\mathrm{TM}}$ Origin 6.0 software (Microcal Software Inc., Northampton, MA, USA). Statistical analysis was done with IBM ${ }^{\circledR}$ SPSS $^{\circledR}$ software (IBM Corporation, Somer, NY, USA) by Student's t-test and One-way ANOVA. Statistical significance was established when $p<0.05$. Bonferroni post-hoc analysis was used for ANOVA.

\section{Results}

\subsection{Systematic Review}

Of all ninety articles identified in the primary search (Pubmed $=76$, Trip Database $=5$, Lilacs $=9$, Cochrane Library $=0$ ), we selected 12 of the experimental studies and one clinical trial (a pilot study on primary biliary cirrhosis). After full-text revision, we selected 11 articles for data discussion (Figure 1). All of them were on experimental studies on BDL rodents, as described in Table 1. Despite use of synonyms terms to retrieve a larger number of articles, we did not have more available information. Meta-analysis was not possible because of different animal species, route of administration, time of exposure, or methodology.

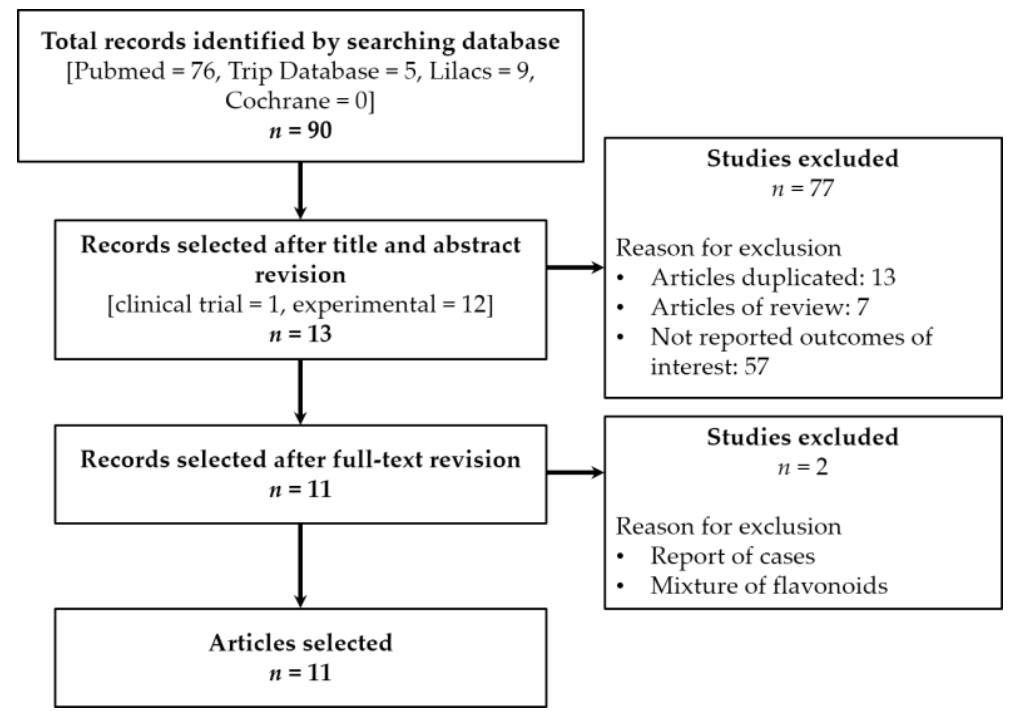

Figure 1. Flowchart showing the selection process for included studies on this systematic review. 
Table 1. Efficacy endpoints studied on selected articles of systematic review.

\begin{tabular}{|c|c|c|c|c|c|c|c|c|c|}
\hline \multirow[b]{2}{*}{ No } & \multirow[b]{2}{*}{ Chemical Structure } & \multirow{2}{*}{$\begin{array}{l}\text { Compound } \\
\text { Name }\end{array}$} & \multirow{2}{*}{$\begin{array}{c}\text { Dose } \\
\text { Applied }\end{array}$} & \multirow[b]{2}{*}{ Species } & \multicolumn{4}{|c|}{ Efficacy Endpoints } & \multirow[b]{2}{*}{ Reference } \\
\hline & & & & & $\begin{array}{c}\text { Liver } \\
\text { Function }\end{array}$ & Fibrosis & $\begin{array}{l}\text { Oxidative } \\
\text { Stress }\end{array}$ & Inflammation & \\
\hline 1 & & Diosmin & $\begin{array}{c}100 \\
\mathrm{mg} / \mathrm{kg} / \text { day, } \\
\text { p.o. for } \\
28 \text { days }\end{array}$ & Wistar rat & $X$ & $X$ & $x$ & $x$ & Ali et al 2018 \\
\hline 2 & \multirow{3}{*}{ OH } & \multirow{3}{*}{ Quercetin } & $\begin{array}{c}30 \\
\mathrm{mg} / \mathrm{kg} / \text { day } \\
\text { p.o. for } \\
28 \text { days }\end{array}$ & Wistar rat & $X$ & $X$ & $x$ & & $\begin{array}{c}\text { Kabirifar et al } \\
2017\end{array}$ \\
\hline 3 & & & $\begin{array}{c}25 \\
\mathrm{mg} / \mathrm{kg} / \text { day } \\
\mathrm{p} . \mathrm{o} . \text { for } \\
28 \text { days }\end{array}$ & $\begin{array}{c}\text { Sprague } \\
\text { Dawley rat }\end{array}$ & $X$ & $x$ & $X$ & $x$ & Lin et al 2014 \\
\hline 4 & & & $\begin{array}{l}75,150,300 \\
\mu \mathrm{mol} / \mathrm{kg} / \text { day } \\
\text { i.p. for } \\
28 \text { days }\end{array}$ & Wistar rat & $x$ & $x$ & $x$ & & Peres et al 2000 \\
\hline 5 & & Rutin & $\begin{array}{l}25 \mathrm{mg} / \mathrm{kg} / \text { day } \\
\text { p.o. for } \\
28 \text { days * }\end{array}$ & $\begin{array}{c}\text { Sprague } \\
\text { Dawley rat }\end{array}$ & $X$ & $X$ & $x$ & $x$ & Pan et al 2014 \\
\hline 6 & & Genistein & $\begin{array}{c}5 \\
\mu \mathrm{g} / \mathrm{rat} / \text { day } \\
\text { p.o. for } \\
56 \text { days }\end{array}$ & Wistar rat & $x$ & $x$ & & & Salas et al 2007 \\
\hline 7 & & Silybin/ & $\begin{array}{l}0.4 \mathrm{~g} / \mathrm{kg} \text { ad } \\
\text { libitum p.o. } \\
\text { for } 28 \text { days }\end{array}$ & Wistar rat & & & $x$ & & $\begin{array}{c}\text { Serviddio et al } \\
2014\end{array}$ \\
\hline 8 & & Silibinin & $\begin{array}{l}\text { Dose not } \\
\text { determined } \\
\text { for } 28 \text { days }\end{array}$ & Wistar rat & & & & $x$ & $\begin{array}{c}\text { Stanca et al } \\
2013\end{array}$ \\
\hline 9 & & Epigallo- & $\begin{array}{l}30 \mathrm{mg} / \mathrm{kg} / \text { day } \\
\text { i.p. for } \\
14 \text { days }\end{array}$ & $\begin{array}{l}\text { C57BL/ } 6 \\
\text { mice }\end{array}$ & & $x$ & $x$ & $x$ & Shen et al 2015 \\
\hline 10 & & $\begin{array}{l}\text { catechin } \\
\text { 3-gallate }\end{array}$ & $\begin{array}{c}25 \\
\mathrm{mg} / \mathrm{kg} / \text { day } \\
\text { p.o. for } \\
14 \text { days }\end{array}$ & $\begin{array}{c}\text { Sprague } \\
\text { Dawley rat }\end{array}$ & $x$ & $x$ & & $x$ & Yu et al 2015 \\
\hline 11 & & Baicalin & $\begin{array}{c}50 \\
\mathrm{mg} / \mathrm{kg} / \text { day } \\
\text { i.p. for } \\
14 \text { days }\end{array}$ & $\begin{array}{l}\text { C57BL } / 6 \\
\text { mice }\end{array}$ & & $x$ & $x$ & $x$ & Shen et al 2017 \\
\hline
\end{tabular}

* Compound administration began 1 week before surgery and 3 weeks postoperative. ${ }^{* *}$ Compound administration began $2 \mathrm{~h}$ before surgery and 14 days postoperative.

The major flavonoids identified from this search were diosmin, bacailin, quercetin, epigallocatechin 3-gallate, silybin or silibinin (major active component of silymarin), rutin (quercetin-3-O-rutinoside), and genistein (Table 1). Interestingly, no evidence was found about NG, one of the most naturally occurring flavonoid studied due of its health benefits on metabolic and cardiovascular diseases (Figure 2). This no evidence scenario encouraged us to evaluate NG as candidate for drug discovery, and contribute to experimental pharmacological data of flavonoids. 


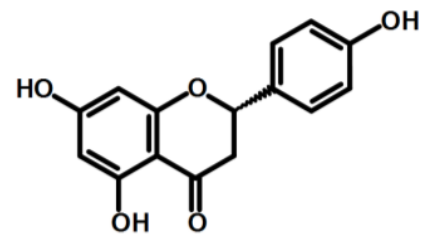

Figure 2. Chemical structure of naringenin (NG).

The biological processes altered on obstructive cholestasis are liver function, extracellular matrix components processing, redox status, and inflammation balance [3]. In this context, only diosmin, quercetin and rutin were evaluated for all these components (Table 1). Lin et al. showed that quercetin supplementation produced alleviation of liver histological integrity, serum biomarkers stabilization, reduction of fibrotic and inflammatory processes, and resolution of oxidative stress probably by modulation of bile duct proliferation and ductal reaction, blockade of mitogenic and fibrogenic signaling, and antioxidant effect [19]. Additionally, they evaluated rutin (quercetin-3-O-rutinoside), the O-glycoside compound that combine quercetin and disaccharide rutinose, on the same model and evaluated the same endpoints. The evidence showed that rutin had similar effects taking into account that it is converted to quercetin during metabolism [20].

On the other hand, Ali et al. reported data on efficacy of diosmin alone or in combination with sildenafil (erectile dysfunction approved drug with antioxidant and anti-inflammatory properties [21,22]) on the same model. Interestingly, diosmin alone was able to restore redox homeostasis by regulation of antioxidant enzymes GSR and SOD, a putative mechanism proposed for this molecule [23].

In order to compare parameters of the liver function and metabolic status on BDL-treated animals, we show tables of percentage change of each parameter vs. untreated cholestatic rats (Tables 2 and 3). It should be noticed that only one study reported mortality as valid endpoint for evaluation of experimental efficacy [23]. Additionally, ductal enzymes AP and GGT were missing on several studies despite these biomarkers are pivotal for cholestasis diagnostic [24].

Table 2. Percentage changes of liver function parameters induced by flavonoids on BDL model.

\begin{tabular}{|c|c|c|c|c|c|c|c|c|}
\hline No & Reference & Compound & \multicolumn{6}{|c|}{ Change \% } \\
\hline 2 & Kabirifar et al 2017 & Quercetin & 32.89 & 34.32 & 44.44 & ND & ND & ND \\
\hline 3 & Lin et al 2014 & Quercetin & 30.05 & 35.98 & ND & 55.87 & 36.26 & ND \\
\hline 6 & Salas et al 2007 & Genistein & 51.53 & ND & 59.88 & 73.68 & 68.97 & ND \\
\hline 7 & Serviddio et al 2014 & Silybin/Silibinin & ND & ND & ND & ND & ND & ND \\
\hline 8 & Stanca et al 2013 & Silybin/Silibinin & 30.76 & 23.68 & 27.78 & ND & 39.76 & ND \\
\hline 9 & Shen et al 2015 & $\begin{array}{l}\text { Epigallocatechin } \\
\text { 3-Gallate }\end{array}$ & ND & ND & ND & ND & ND & ND \\
\hline
\end{tabular}

$\mathrm{ND}$, not determined; NG, Naringenin; ALT, alanine transaminase; AST, aspartate transaminase; AP, alkaline phosphatase; GGT, gamma glutamyltranspeptidase. * Only was considered dose $150 \mu \mathrm{g} / \mathrm{mL}$ for this analysis since this dose was administered for 28 days. Negative values means an augmentation of the parameter in comparison with untreated cholestatic animals. 
Table 3. Percentage changes of metabolic parameters induced by flavonoids on BDL model.

\begin{tabular}{cccccccccc}
\hline \multirow{2}{*}{ No } & \multirow{2}{*}{ Reference } & \multirow{2}{*}{ Compound } & \multicolumn{7}{c}{ Change \% } \\
\cline { 4 - 9 } & & & Glucose & Cholesterol & Triglycerides & Insulin & VLDL & LDL & HDL \\
\hline 3 & Lin et al 2014 & Quercetin & ND & 14.78 & 26.47 & ND & ND & ND & ND \\
5 & Pan et al 2014 & Rutin & ND & 19.13 & 25.00 & ND & ND & ND & ND \\
10 & Yu et al 2015 & Epigallocatechin & ND & 0.69 & ND & ND & ND & 0.74 & -18.52 \\
12 & Current article & NG & -2.51 & 36.33 & 29.43 & 44.44 & 29.43 & 58.44 & -48.50 \\
\hline
\end{tabular}

ND, not determined; NG, naringenin; VLDL, very low density lipoprotein; LDL, low density lipoprotein; HDL, high density lipoprotein. Negative values means an augmentation of the parameter in comparison with untreated cholestatic animals.

Flavonoids showed a good performance in hepatoprotection since almost all compounds showed a marked serum decrease of the liver and ductal enzymes (about $50 \%$ on average). In accordance with these data, it seems that genistein $(5 \mu \mathrm{g} / \mathrm{rat} /$ day, p.o. $)$ and quercetin $(150 \mu \mathrm{mol} / \mathrm{kg} /$ day, i.p. $)$ had a better performance than other flavonoids; however, intraperitoneal high dose (about $45 \mathrm{mg}$ daily), and a confusing mode of administration (it began four weeks before biliary obstruction and was continued for a further four weeks) were inconclusive $[25,26]$.

It is important to mention that quantification of metabolic biomarkers such as cholesterol, depicts indirect improvements on bile acid synthesis; however, metabolites such as glucose, triglycerides, and lipoproteins might determine a correct function of the liver, since this organ plays a central role in lipid and carbohydrate metabolism [24]. As seen above, few investigations consider metabolic parameters as pivotal endpoints for the evaluation of efficacy. Only three studies measured serum cholesterol, two measured triglycerides, and one measured lipoprotein content (LDL and HDL) (Table 3).

Further, it was remarkable to consider that risk of bias assessment show that the majority of studies assessed had a high risk for selection, performance, and detection biases (Figure S1). This evidence exposes an unmet need to improve the quality of the experimental protocols for most confident information in drug discovery. This was another reason for not including a meta-analysis in this investigation.

\subsection{Experimental Study}

\subsubsection{Signature of Obstructive Cholestasis in the Rat}

As reported, bile duct obstruction produced significant alterations in serum biomarkers concentration compared with sham-operated rats. Major alterations were decrease of glucose (Figure 3a) and HDL (Figure 3d), as well as increase of total cholesterol (Figure 3b), LDL (Figure 3d), and bilirrubin (Figure 4d) in comparison with the sham group. Triglycerides and VLDL concentrations were unaltered similar to the report by Stedman et al. [27]. Increase of liver enzymes ALT and AST, and bile ductal enzymes GGT and AP were determinant for cholestatic liver disease signature in BDL (Figure 4), due to hepatocellular damage produced by high concentrations of toxic bile acids [28]. 


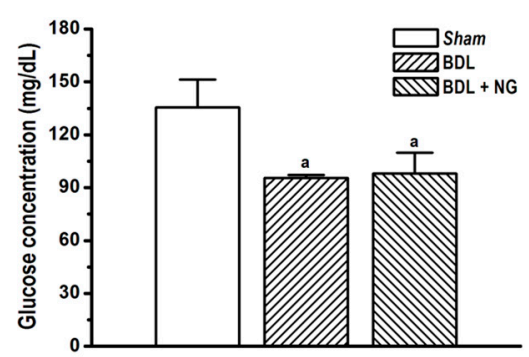

(a)

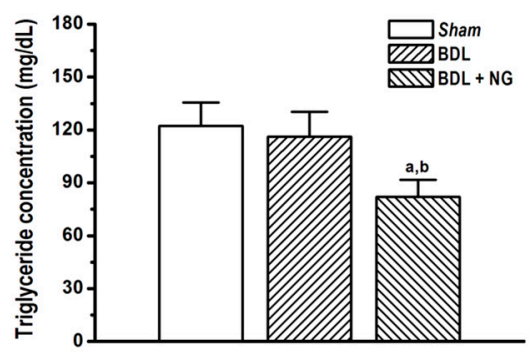

(c)

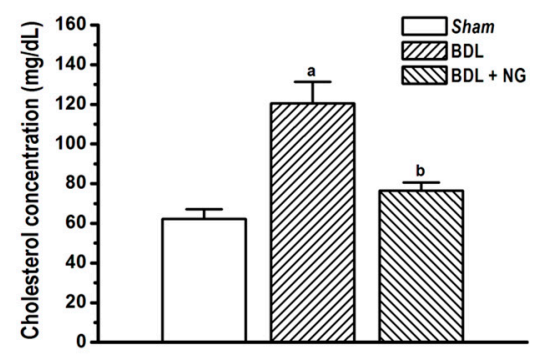

(b)

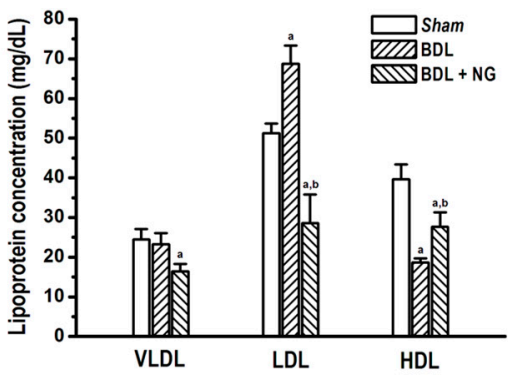

(d)

Figure 3. Metabolic biomarkers quantified on bile duct-ligated (BDL) model after administration of naringenin (NG, $50 \mathrm{mg} / \mathrm{kg} /$ day) for 10 days. (a) Glucose, (b) total cholesterol, (c) triglycerides, (d) lipoprotein (very low-density lipoprotein (VLDL), low-density lipoprotein (LDL), and high-density lipoprotein (HDL)). Data are expressed as means \pm SEM $(n=8-10)$. a: Significantly different from sham control group at $p<0.05$, and b: Significantly different from BDL group at $p<0.05$.

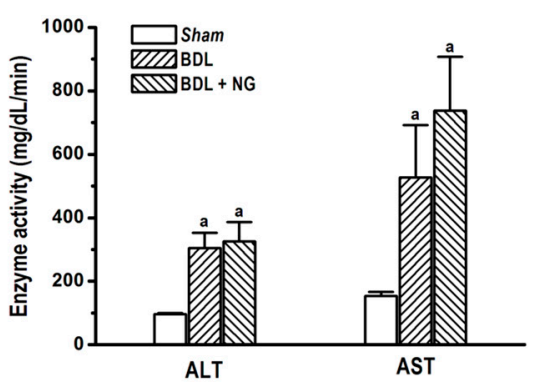

(a)

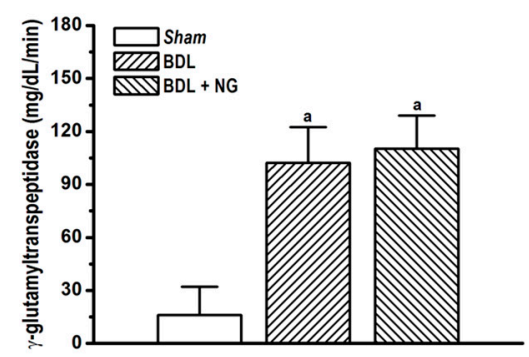

(c)

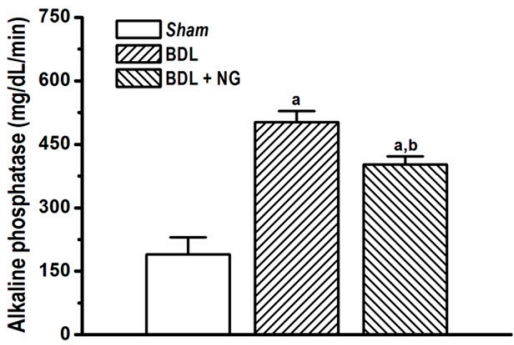

(b)

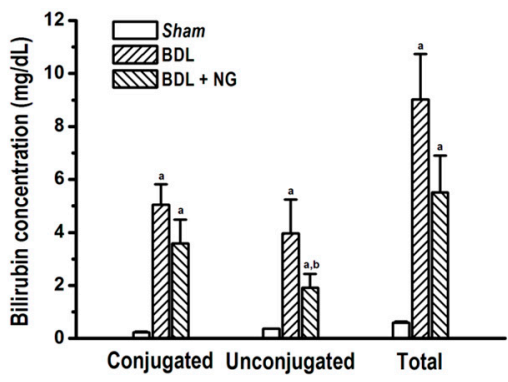

(d)

Figure 4. Liver function and cholestasis biomarkers quantified on bile duct-ligated (BDL) model after administration of naringenin (NG, $50 \mathrm{mg} / \mathrm{kg} /$ day) for 10 days. (a) Transaminases (ALT and AST), (b) alkaline phosphatase, (c) $\gamma$-glutamyltranspeptidase (d), and bilirubin were expressed from each group. Data are expressed as means \pm SEM $(n=8-10)$. a: Significantly different from sham control group at $p$ $<0.05$, and b: Significantly different from BDL group at $p<0.05$. 


\subsubsection{Efficacy of NG in Obstructive Cholestasis}

Naringenin significantly improved serum cholesterol (Figure 4b) and low and high-density lipoproteins (Figure 4d) in the BDL model. Interestingly, despite triglycerides and VLDL were not modified on cholestatic damage, this flavonoid decreased both parameters. Additionally, significant decrease in bilirubin (Figure 4d) and AP activity (Figure 4b) suggests an improvement of liver and bile duct damage.

Finally, biochemical improvements attributed to NG allowed reduced mortality. By contrast, body weight changes along time had no modification. In fact, treated BDL rats suffered more weight loss than the BDL group (Figure 5).

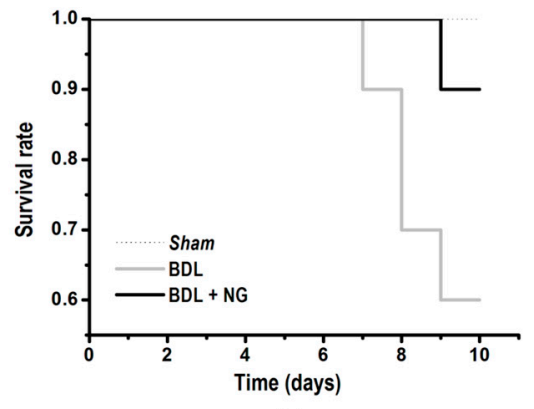

(a)

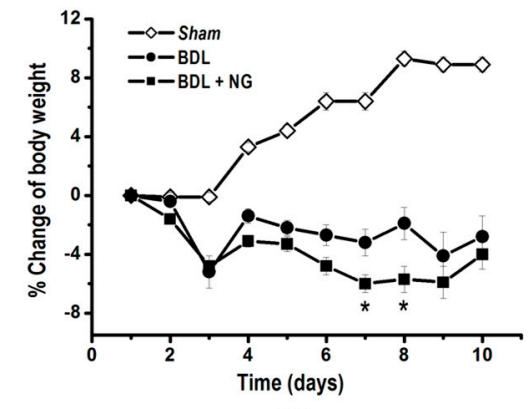

(b)

Figure 5. Survival rate (a), and percentage change of body weight (b) measured after administration of naringenin (NG, $50 \mathrm{mg} / \mathrm{kg} /$ day) for 10 days. *Significantly different from bile duct-ligated (BDL) group at $p<0.05$ ( $n=10$ animals/group).

\section{Discussion}

Flavonoids are naturally occurring compounds with beneficial health effects in chronic diseases, being cardiovascular and metabolic diseases that are better characterized. Further, higher intake of these compounds has been associated with lower mortality rates from specific vascular diseases and cancer [29]. The importance of flavonoid-rich foods consumption in preventing cholestasis mortality remains uncertain. For this reason, we aimed to show the state-of-the-art of flavonoids for the drug design of new anti-cholestatic agents through a systematic review.

Currently, some articles have applied systematic searching in order to analyze proficiency of natural products on specific illnesses (e.g. triterpenes on wound healing) [30]. Recently, Chen et al. reviewed phenylated flavonoids and their biological effects; this investigation focused on structural properties of the phenylated flavonoids and the implication in biological activity. However, no evidence was found on cholestatic liver disease or liver disease related abnormalities [13]. For this reason, the anti-cholestatic effect of flavonoids remains an outstanding issue in drug discovery.

Silymarin has been the most studied flavonoid for liver disease. This extract has been characterized as a potent antioxidant, immunomodulatory, and anti-fibrotic agent indicated as adjuvant treatment for all-causes liver disorders [11]. Our analysis shows that one major component of this extract, silibinin or silybin, improved serum transaminase, AP, and bilirubin in BDL model; which is possible by a decrease of pro-inflammatory lipids (platelet-activating factor, PAF), and improved activity and expression of both lysophosphatidylcholine acyltransferase LPCAT1 and LPCAT2, key enzymes in PAF remodeling [31]. Despite evidence, there is no more investigation about flavonoid-based therapeutic interventions for the treatment of cholestasis. This situation suggests an opportunity for medicinal chemists, computer-aided designers, or organic chemists to evaluate flavonoid as a potential scaffold for new lead compounds.

Our database search shows no evidence for evaluation of flavonoids efficacy and safety in a clinical setting. Only a pilot study $(n=27)$ was found where oral silymarin was assessed in UDCA non-responsive primary biliary cirrhosis (PBC) patients. Despite UDCA therapy for $52.6 \pm 10.4$ 
months, elevation of AP activity (2 times above normal) was persistent, neither adjuvant therapy with silymarin improved clinical endpoints [11]. In this context, diosmin, quercetin, or genistein should be good options since these flavonoids decreased AP activity 40-50\% (Table 2). However, more clinical investigation is still needed to assess this potential.

On the other hand, eleven reports were retrieved from systematic search. The analysis showed a variety of administration and time framework, i.e., some reported pre-operative (one week) and post-operative (three weeks) administration $[19,20]$. This approach might bias in the therapeutic effect assessment, since it began one week before a cholestatic pattern is established. Additionally, animal species were different and possibly crucial for biological behavior. The most used is the Wistar rat (six studies) followed by Sprague Dawley (three studies). Despite Sprague Dawley was developed from Wistar strain, data show that Wistar strain is prone for metabolic impairments [32]. This should be relevant in taking into account the metabolic component of cholestasis [33,34].

As mentioned, metabolic impairment is a pivotal alteration on obstructive cholestasis. Alterations in glucose, cholesterol, LDL, and HDL were observed in the BDL group (Figure 4). Modification of cholesterol and lipoprotein on cholestasis by bile duct ligation surgery is known [35]; also, high concentration of plasma insulin [36,37] and low concentration of glucose [38] have been reported for this model. In contrast, other studies reported contradictory values suggesting a wide metabolic disparity between species, rodent strain, and time of damage exposure [38,39]. In addition, it has been established that intrahepatic cholestasis of pregnancy (ICP) and PBC are associated with impaired metabolic profile, including glucose intolerance and dyslipidemia $[33,34]$. Our analysis showed few data on metabolic parameters for BDL (Table 3).

This is the first time that NG is evaluated in a BDL model, despite that a simple review about beneficial effects of this flavonoid in ethanol- and carbon tetrachloride-induced liver diseases and its putative mechanisms was published with no evidence about obstructive cholestasis [40]. Mulvihill and colleagues reported similar effects in their studies using LDL receptor-null (LDL ${ }^{-/}$) mice fed with a Western high caloric diet, which expressed metabolic impairments as dyslipidemia (increased VLDL and LDL), hyperinsulinemia, and weight gain vs. wild-type littermates. Treatment with NG $1 \%$ or $3 \%(\mathrm{wt} / \mathrm{wt}$ ) improved triglyceride, total cholesterol, and lipoprotein concentrations after four weeks. In contrast, HDL was unaltered in animals with the Western diet, and NG did not modify this condition [41]. Our findings contribute for the beneficial metabolic effects induced by this flavonoid, taking into account that cholestasis have a distinct etiology and target organ than the diet-induced dyslipidemia.

Finally, the precise mechanism by which flavonoids exert their hepatoprotective effects is unclear yet. However, there is evidence suggesting that flavonoids might improve imbalance in oxidant/antioxidant status. For example, Kabirifar et al. reported that quercetin might improve the antioxidant capacity of the liver tissue by decreasing the activity of NADPH oxidase 1 (NOX1), a major intracellular producer of reactive oxygen species [42], and the expression of its activator Rac1. Further, an increase of the antioxidant enzymes catalase and glutathione superoxide dismutase (SOD) was reported [43]. Lin et al. showed similar evidences where an elevated mRNA expression of Mn-SOD, $\mathrm{Cu} / \mathrm{Zn}-\mathrm{SOD}$, and catalase was observed. [19] On the other hand, it has been reported that flavonoids exert a regulation of inflammatory response and deposition of extracellular matrix by the decrease of mitogenic IL-1 $\beta$ and fibrogenic TGF- $\beta 1$ expression and down-regulated BDL-induced hepatic Smad2/3 phosphorylation. [19] More investigation must be encouraged to promote comprehensive studies that describe the beneficial effects of flavonoids and its mechanism.

\section{Conclusions}

Flavonoids comprise a group of natural products with promising efficacy for the management of cholestatic liver disease. More clinical and experimental investigation should be driven to promote the drug design of flavonoid-based pharmaceuticals for the treatment of these pathologies with the lowest risk of bias. Naringenin is a flavonoid with specific beneficial effects on liver function and metabolic 
flow altered in cholestasis. Further investigation needs is required to characterize its pharmacological mechanism and applicability in a clinical setting.

Supplementary Materials: The following are available online at http:/ / www.mdpi.com/2218-273X/9/3/102/s1, Figure S1: SYRCLE's tool for assessing risk of bias of the selected studies, Table S1: PICO strategy developed for systematic review.

Author Contributions: J.C.S.-S.; methodology, data curacy, writing first draft, S.E.-S; validation, supervision, administration of the project, S.G.-J; methodology, S.M.; methodology, J.G.-Z; methodology, and R.V.-M.; supervision, verification.

Funding: This study was financed by a grant from CONACYT (SEP-2003-C02-43440/280) and PROMEP-SEP. J.C.S.-S. is a CONACYT fellow (reference number: 198277).

Acknowledgments: Juan Carlos Sánchez-Salgado and Samuel Estrada-Soto belong to Red Nacional de Investigación Preclínica de Productos Naturales.

Conflicts of Interest: All authors declare do not have some conflict of interest.

\section{References}

1. Williams, R. Global challenges in liver disease. Hepatology 2006, 44, 521-526. [CrossRef]

2. Araújo, A.R.; Rosso, N.; Bedogni, G.; Tiribelli, C.; Bellentani, S. Global epidemiology of non-alcoholic fatty liver disease/non-alcoholic steatohepatitis: What we need in the future. Liver Int. 2018, 38, 47-51. [CrossRef]

3. Abshagen, K.; König, M.; Hoppe, A.; Müller, I.; Ebert, M.; Weng, H.; Holzhütter, H.-G.; Zanger, U.M.; Bode, J.; Vollmar, B.; et al. Pathobiochemical signatures of cholestatic liver disease in bile duct ligated mice. BMC Syst. Biol. 2015, 9, 83. [CrossRef] [PubMed]

4. Heathcote, E.J. Diagnosis and management of cholestatic liver disease. Clin. Gastroenterol. Hepatol. 2007, 5, 776-782. [CrossRef] [PubMed]

5. Bosoi, C.R.; Oliveira, M.M.; Ochoa-Sanchez, R.; Tremblay, M.; Ten Have, G.A.; Deutz, N.E.; Rose, C.F.; Bemeur, C. The bile duct ligated rat: A relevant model to study muscle mass loss in cirrhosis. Metab. Brain Dis. 2017, 32, 513-518. [CrossRef] [PubMed]

6. Wang, H.; Vohra, B.P.S.; Zhang, Y.; Heuckeroth, R.O. Transcriptional profiling after bile duct ligation identifies PAI-1 as a contributor to cholestatic injury in mice. Hepatology 2005, 42, 1099-1108. [CrossRef] [PubMed]

7. Rudic, J.S.; Poropat, G.; Krstic, M.N.; Bjelakovic, G.; Gluud, C. Ursodeoxycholic acid for primary biliary cirrhosis. Cochrane Database Syst. Rev. 2012, 12, CD000551. [CrossRef] [PubMed]

8. Thompson, J.N.; Cohen, J.; Blenkharn, J.I.; McConnell, J.S.; Barr, J.; Blumgart, L.H. A randomized clinical trial of oral ursodeoxycholic acid in obstructive jaundice. Br. J. Surg. 1986, 73, 634-636. [CrossRef]

9. Federico, A.; Dallio, M.; Loguercio, C. Silymarin/Silybin and Chronic Liver Disease: A Marriage of Many Years. Molecules 2017, 22, 191. [CrossRef] [PubMed]

10. Crocenzi, F.A.; Roma, M.G. Silymarin as a new hepatoprotective agent in experimental cholestasis: New possibilities for an ancient medication. Curr. Med. Chem. 2006, 13, 1055-1074. [CrossRef]

11. Angulo, P.; Patel, T.; Jorgensen, R.A.; Therneau, T.M.; Lindor, K.D. Silymarin in the treatment of patients with primary biliary cirrhosis with a suboptimal response to ursodeoxycholic acid. Hepatology 2000, 32, 897-900. [CrossRef] [PubMed]

12. Schuler, J.; Hudson, M.L.; Schwartz, D.; Samudrala, R. A Systematic Review of Computational Drug Discovery, Development, and Repurposing for Ebola Virus Disease Treatment. Molecules 2017, 22, 177. [CrossRef] [PubMed]

13. Chen, X.; Mukwaya, E.; Wong, M.-S.; Zhang, Y. A systematic review on biological activities of prenylated flavonoids. Pharm. Biol. 2014, 52, 655-660. [CrossRef]

14. Sánchez-Salgado, J.C.; Ortiz-Andrade, R.R.; Aguirre-Crespo, F.; Vergara-Galicia, J.; León-Rivera, I.; Montes, S.; Villalobos-Molina, R.; Estrada-Soto, S. Hypoglycemic, vasorelaxant and hepatoprotective effects of Cochlospermum vitifolium (Willd) Sprengel: A potential agent for the treatment of metabolic syndrome. J. Ethnopharmacol. 2007, 109, 400-405.

15. Sánchez-Salgado, J.C.; Castillo-España, P.; Ibarra-Barajas, M.; Villalobos-Molina, R.; Estrada-Soto, S. Cochlospermum vitifolium induces vasorelaxant and antihypertensive effects mainly by activation of NO/cGMP signaling pathway. J. Ethnopharmacol. 2010, 130, 477-484. [CrossRef] [PubMed] 
16. Aguilar-Guadarrama, A.B.; Rios, M.Y. Flavonoids, Sterols and Lignans from Cochlospermum vitifolium and Their Relationship with Its Liver Activity. Molecules 2018, 23, 1952. [CrossRef] [PubMed]

17. Hooijmans, C.R.; Rovers, M.M.; de Vries, R.B.M.; Leenaars, M.; Ritskes-Hoitinga, M.; Langendam, M.W. SYRCLE's risk of bias tool for animal studies. BMC Med. Res. Methodol. 2014, 14, 43. [CrossRef]

18. Rivera-Mancía, S.; Montes, S.; Méndez-Armenta, M.; Muriel, P.; Ríos, C. Morphological changes of rat astrocytes induced by liver damage but not by manganese chloride exposure. Metab. Brain. Dis. 2009, 24, 243-255. [CrossRef]

19. Lin, S.-Y.; Wang, Y.-Y.; Chen, W.-Y.; Chuang, Y.-H.; Pan, P.-H.; Chen, C.-J. Beneficial effect of quercetin on cholestatic liver injury. J. Nutr. Biochem. 2014, 25, 1183-1195. [CrossRef]

20. Pan, P.-H.; Lin, S.-Y.; Wang, Y.-Y.; Chen, W.-Y.; Chuang, Y.-H.; Wu, C.-C.; Chen, C.-J. Protective effects of rutin on liver injury induced by biliary obstruction in rats. Free Radic. Biol. Med. 2014, 73, 106-116. [CrossRef]

21. Zahran, M.H.; Hussein, A.M.; Barakat, N.; Awadalla, A.; Khater, S.; Harraz, A.; Shokeir, A.A. Sildenafil activates antioxidant and antiapoptotic genes and inhibits proinflammatory cytokine genes in a rat model of renal ischemia/reperfusion injury. Int. Urol. Nephrol. 2015, 47, 1907-1915. [CrossRef] [PubMed]

22. Kaur, M.; Singh, A.; Kumar, B.; Singh, S.K.; Bhatia, A.; Gulati, M.; Prakash, T.; Bawa, P.; Malik, A.H. Protective effect of co-administration of curcumin and sildenafil in alcohol induced neuropathy in rats. Eur. J. Pharmacol. 2017, 805, 58-66. [CrossRef]

23. Ali, F.E.M.; Azouz, A.A.; Bakr, A.G.; Abo-Youssef, A.M.; Hemeida, R.A.M. Hepatoprotective effects of diosmin and/or sildenafil against cholestatic liver cirrhosis: The role of Keap-1/Nrf-2 and P38-MAPK/NF-kB/iNOS signaling pathway. Food Chem. Toxicol. 2018, 120, 294-304. [CrossRef] [PubMed]

24. Lawrence, Y.A.; Steiner, J.M. Laboratory Evaluation of the Liver. Vet. Clin. North Am. Small Anim. Pract. 2017, 47, 539-553. [CrossRef] [PubMed]

25. Salas, A.L.; Ocampo, G.; Fariña, G.G.; Reyes-Esparza, J.; Rodríguez-Fragoso, L. Genistein decreases liver fibrosis and cholestasis induced by prolonged biliary obstruction in the rat. Ann. Hepatol. 2007, 6, 41-47.

26. Peres, W.; Tuñón, M.J.; Collado, P.S.; Herrmann, S.; Marroni, N.; González-Gallego, J. The flavonoid quercetin ameliorates liver damage in rats with biliary obstruction. J. Hepatol. 2000, 33, 742-750. [CrossRef]

27. Stedman, C.; Liddle, C.; Coulter, S.; Sonoda, J.; Alvarez, J.G.; Evans, R.M.; Downes, M. Benefit of farnesoid X receptor inhibition in obstructive cholestasis. Proc. Natl. Acad. Sci. USA 2006, 103, 11323-11328. [CrossRef]

28. Higuchi, H.; Gores, G.J. Bile acid regulation of hepatic physiology: IV. Bile acids and death receptors. Am. J. Physiol. Gastrointest. Liver Physiol. 2003, 284, G734-G738.

29. Ivey, K.L.; Jensen, M.K.; Hodgson, J.M.; Eliassen, A.H.; Cassidy, A.; Rimm, E.B. Association of flavonoid-rich foods and flavonoids with risk of all-cause mortality. Br. J. Nutr. 2017, 117, 1470-1477. [CrossRef]

30. Agra, L.C.; Ferro, J.N.S.; Barbosa, F.T.; Barreto, E. Triterpenes with healing activity: A systematic review. J. Dermatolog. Treat. 2015, 26, 465-470. [CrossRef]

31. Stanca, E.; Serviddio, G.; Bellanti, F.; Vendemiale, G.; Siculella, L.; Giudetti, A.M. Down-regulation of LPCAT expression increases platelet-activating factor level in cirrhotic rat liver: potential antiinflammatory effect of silybin. Biochim. Biophys. Acta. 2013, 1832, 2019-2026. [CrossRef] [PubMed]

32. Marques, C.; Meireles, M.; Norberto, S.; Leite, J.; Freitas, J.; Pestana, D.; Faria, A.; Calhau, C. High-fat diet-induced obesity Rat model: A comparison between Wistar and Sprague-Dawley Rat. Adipocyte 2015, 5, 11-21. [CrossRef] [PubMed]

33. Menżyk, T.; Bator, M.; Derra, A.; Kierach, R.; Kukla, M. The role of metabolic disorders in the pathogenesis of intrahepatic cholestasis of pregnancy. Clin. Exp. Hepatol. 2018, 4, 217-223. [CrossRef] [PubMed]

34. Vignoli, A.; Orlandini, B.; Tenori, L.; Biagini, M.R.; Milani, S.; Renzi, D.; Luchinat, C.; Calabrò, A.S. The metabolic signature of Primary Biliary Cholangitis and its comparison with Coeliac Disease. J. Proteome Res. 2018, 18, 1228-1236. [CrossRef] [PubMed]

35. Bauer, J.E.; Meyer, D.J.; Campbell, M.; McMurphy, R. Serum lipid and lipoprotein changes in ponies with experimentally induced liver disease. Am. J. Vet. Res. 1990, 51, 1380-1384.

36. Jessen, N.; Buhl, E.S.; Schmitz, O.; Lund, S. Impaired insulin action despite upregulation of proximal insulin signaling: novel insights into skeletal muscle insulin resistance in liver cirrhosis. J. Hepatol. 2006, 45, 797-804. [CrossRef] [PubMed]

37. Lin, S.-Y.; Sheu, W.H.-H.; Chen, W.-Y.; Lee, F.-Y.; Huang, C.-J. Stimulated resistin expression in white adipose of rats with bile duct ligation-induced liver cirrhosis: relationship to cirrhotic hyperinsulinemia and increased tumor necrosis factor-alpha. Mol. Cell. Endocrinol. 2005, 232, 1-8. [CrossRef] 
38. Enochsson, L.; Isaksson, B.; Strömmer, L.; Erlanson-Albertsson, C.; Permert, J. Bile duct obstruction is associated with early postoperative upregulation of liver uncoupling protein-2 and reduced circulating glucose concentration in the rat. Nutrition 2010, 26, 405-410. [CrossRef]

39. Catala, J.; Daumas, M.; Chanh, A.P.; Lasserre, B.; Hollande, E. Insulin and glucagon impairments in relation with islet cells morphological modifications following long term pancreatic duct ligation in the rabbit-a model of non-insulin-dependent diabetes. Int. J. Exp. Diabetes Res. 2001, 2, 101-112. [CrossRef]

40. Hernández-Aquino, E.; Muriel, P. Beneficial effects of naringenin in liver diseases: Molecular mechanisms. World J. Gastroenterol. 2018, 24, 1679-1707. [CrossRef]

41. Mulvihill, E.E.; Allister, E.M.; Sutherland, B.G.; Telford, D.E.; Sawyez, C.G.; Edwards, J.Y.; Markle, J.M.; Hegele, R.A.; Huff, M.W. Naringenin prevents dyslipidemia, apolipoprotein B overproduction, and hyperinsulinemia in LDL receptor-null mice with diet-induced insulin resistance. Diabetes 2009, 58, 2198-2210. [CrossRef] [PubMed]

42. Choi, S.S.; Sicklick, J.K.; Ma, Q.; Yang, L.; Huang, J.; Qi, Y.; Chen, W.; Li, Y.-X.; Goldschmidt-Clermont, P.J.; Diehl, A.M. Sustained activation of Rac1 in hepatic stellate cells promotes liver injury and fibrosis in mice. Hepatology 2006, 44, 1267-1277. [CrossRef] [PubMed]

43. Kabirifar, R.; Ghoreshi, Z.-A.-S.; Safari, F.; Karimollah, A.; Moradi, A.; Eskandari-Nasab, E. Quercetin protects liver injury induced by bile duct ligation via attenuation of Rac1 and NADPH oxidase1 expression in rats. HBPD INT 2017, 16, 88-95. [CrossRef]

(C) 2019 by the authors. Licensee MDPI, Basel, Switzerland. This article is an open access article distributed under the terms and conditions of the Creative Commons Attribution (CC BY) license (http://creativecommons.org/licenses/by/4.0/). 